\title{
Sources of variability in quantification of CMR infarct size and their impact on sample size calculations - reproducibility among three core laboratories
}

\author{
Igor Klem ${ }^{3 *}$, Einar Heiberg ${ }^{1}$, Lowie van Assche ${ }^{3}$, Galen Wagner ${ }^{3}$, Michele Parker $^{3}$, Han W Kim³ ${ }^{3}$ John D Grizzard², \\ Håkan Arheden', Raymond Kim,4
}

From 18th Annual SCMR Scientific Sessions

Nice, France. 4-7 February 2015

\section{Background}

Infarct size is increasingly used as an efficacy endpoint in randomized trials comparing acute myocardial infarct (AMI) therapies. Infarct size, depicted by delayedenhancement-CMR, is quantified using manual planimetry (MANUAL), visual scoring (VISUAL), or automated techniques using signal-intensity thresholding to define infarct borders (AUTO). Although AUTO is considered the most reproducible, prior studies did not account for the subjective determination of endocardial/epicardial borders, which all methods require. For MANUAL and VISUAL, prior studies have not explicitly defined how to treat intermediate signal-intensities due to partial volume. We wanted to assess sources of variability among 6 methods in quantification of AMI size, and illustrate the significance of these findings on sample size calculations for clinical trials.

\section{Methods}

Scans of 30 AMI patients and 12 controls were sent to 3 core-laboratories. Infarct size was measured using 6 methods, each separated by $>2$-months time, as follows $(n=540$ evaluations): [1] AUTO; [2] AUTO-UC (user correction for endocardial border pixels, no-reflow, etc.); [3] MANUAL; [4] MANUAL-ISI (adjustment for intermediate signalintensities); [5] VISUAL; [6] VISUAL-ISI. Reproducibility was assessed by calculating the coefficient of variation $(\mathrm{CV})$ and intraclass correlation coefficient (ICC). Using standard

${ }^{3}$ Cardiology/Cardiovascular MRI Center, Duke University Medical Center, Durham, NC, USA

Full list of author information is available at the end of the article variance components analysis, we calculated the variance between-patients and within-patients separately.

\section{Results}

$>$ Mean infarct size varied between $16.8 \%$ and $27.2 \%$ of LV mass depending on the method. Even AUTO (no user interaction for infarct borders) resulted in significant within-patient variability given the need to delineate endocardial/epicardial contours $(\mathrm{CV}=10.6 \%)$. Adding user input to correct computer generated infarct borders resulted in a mild improvement in reproducibility (AUTO-UC: $\mathrm{CV}=8.3 \%$; $\mathrm{p}=0.045$ for comparison with AUTO). For manual and visual categories, explicitly adjusting for intermediate signal-intensities led to improved reproducibility (MANUAL-ISI vs MANUAL: $\mathrm{CV}=8.3 \%$ vs $14.4 \% ; \mathrm{p}=0.03$; VISUAL-ISI vs VISUAL: $\mathrm{CV}=8.4 \%$ vs $10.9 \% ; \mathrm{p}=0.01$ ). When the best techniques in each category were compared, reproducibility was similar (AUTO-UC, MANUAL-ISI, and VISUAL-ISI: CV=8.3\%, $8.3 \%, 8.4 \%$, respectively). For these 3 techniques the within-patient variability due to the quantification method was less than $10 \%$ of the total variability. Hence, there were minimal differences between these methods in the calculated sample sizes needed to detect a $3 \%, 5 \%$, and $7 \%$ absolute reduction in acute infarct size.

\section{Conclusions}

Among CMR core-laboratories, an important source of variability in infarct size quantification is the subjective delineation of endocardial/epicardial borders. When intermediate signal intensities are considered in manual 
Table 1 Summary of Reproducibility Analysis

\begin{tabular}{ccc}
\hline & CV & ICC \\
\hline AUTO & $10.6 \%$ & $0.91[0.86,0.95]$ \\
\hline AUTO-UC & $8.3 \%$ & $0.96[0.93,0.98]$ \\
\hline MANUAL & $14.4 \%$ & $0.87[0.79,0.93]$ \\
\hline MANUAL-ISI & $8.3 \%$ & $0.94[0.90,0.97]$ \\
\hline VISUAL & $10.9 \%$ & $0.85[0.77,0.92]$ \\
\hline VISUAL-ISI & $8.4 \%$ & $0.90[0.84,0.95]$ \\
\hline
\end{tabular}

$\mathrm{CV}=$ coefficient of variation

ICC=intraclass correlation coefficient, $95 \% \mathrm{Cl}$ in parenthesis

planimetry and visual scoring, reproducibility and impact on sample size are similar to automated techniques.

\section{Funding}

N/A.

\section{Authors' details}

${ }^{1}$ Department of Clinical Physiology, Lund University, Lund University Hospital, Lund, Sweden. ${ }^{2}$ Radiology, Virginia Commonwealth University Health Systems, Richmond, VA, USA. ${ }^{3}$ Cardiology/Cardiovascular MRI Center, Duke University Medical Center, Durham, NC, USA. ${ }^{4}$ Radiology, Duke University Medical Center, Durham, NC, USA.

Published: 3 February 2015

doi:10.1186/1532-429X-17-S1-P84

Cite this article as: Klem et al:: Sources of variability in quantification of CMR infarct size and their impact on sample size calculations reproducibility among three core laboratories. Journal of Cardiovascular Magnetic Resonance 2015 17(Suppl 1):P84.

Submit your next manuscript to BioMed Central and take full advantage of:

- Convenient online submission

- Thorough peer review

- No space constraints or color figure charges

- Immediate publication on acceptance

- Inclusion in PubMed, CAS, Scopus and Google Scholar

- Research which is freely available for redistribution

Submit your manuscript at www.biomedcentral.com/submit
C Biomed Central 